
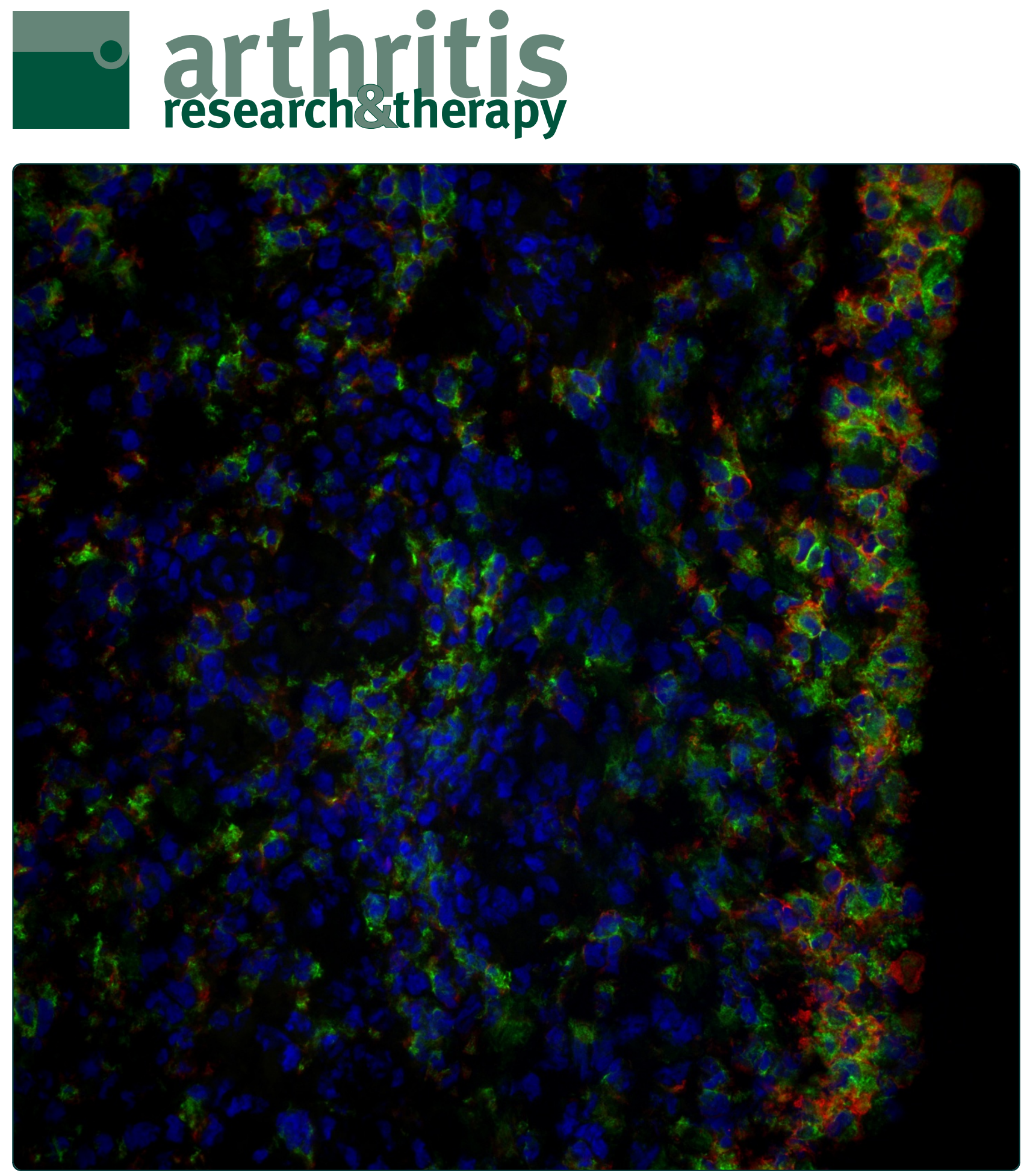

Intimal lining layer macrophages but not synovial sublining macrophages display an IL-10 polarized-like phenotype in chronic synovitis

Ambarus et al. 


\title{
Intimal lining layer macrophages but not synovial sublining macrophages display an IL-10 polarized-like phenotype in chronic synovitis
}

\author{
Carmen A Ambarus ${ }^{1,2^{*}}$, Troy Noordenbos ${ }^{1,2}$, Maria JH de Hair ${ }^{1}$, Paul P Tak ${ }^{1,3}$ and Dominique LP Baeten ${ }^{1,2}$
}

\begin{abstract}
Introduction: Synovial tissue macrophages play a key role in chronic inflammatory arthritis, but the contribution of different macrophage subsets in this process remains largely unknown. The main in vitro polarized macrophage subsets are classically (M1) and alternatively (M2) activated macrophages, the latter comprising interleukin (IL)-4 and IL-10 polarized cells. Here, we aimed to evaluate the polarization status of synovial macrophages in spondyloarthritis (SpA) and rheumatoid arthritis (RA).

Methods: Expression of polarization markers on synovial macrophages, peripheral blood monocytes, and in vitro polarized monocyte-derived macrophages from SpA versus RA patients was assessed by immunohistochemistry and flow cytometry, respectively. The polarization status of the intimal lining layer and the synovial sublining macrophages was assessed by double immunofluorescence staining.

Results: The expression of the IL-10 polarization marker cluster of differentiation 163 (CD163) was increased in SpA compared with RA intimal lining layer, but no differences were found in other $\mathrm{M} 1$ and $\mathrm{M} 2$ markers between the diseases. Furthermore, no significant phenotypic differences in monocytes and in vitro polarized monocyte-derived macrophages were seen between SpA, RA, and healthy controls, indicating that the differential CD163 expression does not reflect a preferential M2 polarization in SpA. More detailed analysis of intimal lining layer macrophages revealed a strong co-expression of the IL-10 polarization markers CD163 and cluster of differentiation 32 (CD32) but not any of the other markers in both SpA and RA. In contrast, synovial sublining macrophages had a more heterogeneous phenotype, with a majority of cells co-expressing M1 and M2 markers.

Conclusions: The intimal lining layer but not synovial sublining macrophages display an IL-10 polarized-like phenotype, with increased CD163 expression in SpA versus RA synovitis. These differences in the distribution of the polarized macrophage subset may contribute to the outcome of chronic synovitis.
\end{abstract}

\section{Introduction}

The normal synovial membrane consists of two distinct structures: the intimal lining layer and the synovial sublining. The normal intimal lining layer comprises fibroblast-like synoviocytes and intimal lining layer macrophages, whereas the synovial sublining consists of connective tissue containing blood vessels, fibroblasts, adipocytes, and a limited number of resident immune cells, such as macrophages and mast cells [1]. Chronic

\footnotetext{
* Correspondence: c.a.ambarus@amc.nl

'Department of Clinical Immunology and Rheumatology, Academic Medical Center/University of Amsterdam, Meibergdreef 9, 1105 AZ Amsterdam, The Netherlands

Full list of author information is available at the end of the article
}

inflammatory arthritis is histologically characterized by marked hyperplasia of the intimal lining layer and massive infiltration of the synovial sublining with innate and adaptive immune cells, which release inflammatory mediators, promote neoangiogenesis, and drive the destruction of adjacent cartilage and bone [2]. Macrophages play a major role in this process because they contribute to the intimal lining layer hyperplasia [3] and are the main producers of key inflammatory mediators, such as tumor necrosis factor (TNF) [4]. Accordingly, the number of synovial macrophages correlates with clinical disease activity $[2,5]$ and decreases after clinically efficient but not placebo treatment in both rheumatoid arthritis (RA) [6-9] and spondyloarthritis (SpA) [10-13]. 
Furthermore, selective macrophage depletion has a strong antiinflammatory effect in animal models of arthritis [14].

Tissue macrophages consist of resident macrophages and monocytes that are recruited in inflammatory conditions and differentiate into macrophages on tissue entry. These macrophages represent a heterogeneous population, as local mediators can prime macrophages during their maturation and thereby shape their subsequent response to various activating stimuli $[15,16]$. Initially, two main polarized macrophage subsets were described based on their pro- versus antiinflammatory functions: classically activated macrophages (M1), which are specialized in the clearance of intracellular pathogens, and alternatively activated macrophages (M2), which have immunoregulatory properties and are involved in scavenging debris, angiogenesis, and tissue repair [17]. The M1 subset is induced mainly by interferon (IFN)- $\gamma\left(M_{\Phi_{\text {IFN- } \gamma}}\right)$, whereas M2 can be induced in vitro either by IL-4 $\left(\mathrm{M}_{\mathrm{IL}-4}\right) / \mathrm{IL}-13$ or by IL-10 $\left(\mathrm{M} \Phi_{\mathrm{IL}-}\right.$ 10) $[17-20]$. Whereas the macrophage polarization has been best described in rodents, we recently validated specific phenotypic markers [21] and distinct functional characteristics (unpublished observations) for these three main in vitro polarized macrophage subsets in humans.

The increasing knowledge of the phenotypic and functional diversity of human macrophages indicates that not only the overall number of macrophages in the inflamed tissue, but also their specific polarization status may determine the disease outcome in terms of severity, chronicity, and tissue damage. Interestingly, we previously described that, despite similar numbers of macrophages in RA and SpA synovitis, a selective overrepresentation of $\mathrm{CD} 163^{+}$macrophages was present in SpA [3,22-25]. CD163, the scavenger receptor for hemoglobin/haptoglobin complexes, is a known marker for IL-10 or M-CSF polarized M2 $[21,26]$. Together with the lower levels of M1-derived proinflammatory cytokines in SpA versus RA synovial fluid [27] and the defective IFN- $\gamma$ signature in SpA monocytes [28], these data suggest a preferential M2 polarization in SpA compared with an M1 polarization in RA. The aim of this study was to test this hypothesis by detailed characterization of distinct macrophage subsets in SpA and RA synovial tissue.

\section{Materials and methods}

\section{Patients and samples}

Peripheral blood samples were obtained from 11 SpA and eight RA patients and nine healthy controls. Synovial biopsies were obtained with small-bore arthroscopy from clinically inflamed knee joints, as previously described [29], and $18 \mathrm{SpA}$ and $20 \mathrm{RA}$ patients were included for the immunohistochemical analysis. All SpA patients fulfilled the criteria of the European Spondyloarthropathy Study Group (ESSG) [30], and all RA patients fulfilled the 1987 ACR classification criteria for RA [31]. Demographic and clinical data of the patients are shown in Table 1 . None of the patients was being treated with biologicals. All patients gave written informed consent to participate to the study, as approved by the Medical Ethics Committee of the Academic Medical Centre/University of Amsterdam.

\section{Immunohistochemistry}

Synovial biopsy samples (six to eight per patient to minimize sampling error) were snap-frozen en bloc and mounted in Jung tissue-freezing medium (Leica Instruments, Nussloch, Germany). The acetone-fixed sections were stained by using mouse monoclonal antibodies directed toward CD68 (clone EBM-11; Dako, Heverlee, The Netherlands), CD64 (clone 10.1; BioLegend, Uithoorn, The Netherlands), CD14 (clone TUK4; Dako), CD163 (clone 5cFAT; BMA Biomedicals, Augst, Switzerland), and CD32 (clone AT10; abcam, Cambridge, UK). Sections were sequentially incubated with a biotinylated secondary antibody, a streptavidin-horseradish peroxidase link (LSAB; Dako), aminoethylcarbazole substrate as chromogen, and hematoxylin as counterstain $[22,25]$. Parallel sections were incubated with isotypeand concentration-matched monoclonal antibodies as negative controls. The expression of CD200R was assessed with immunofluorescence, by using a mouse monoclonal antibody (clone OX108; AbD Serotec, Düsseldorf, Germany). For each cohort, samples were stained in a single run, coded, and scored in a random order on a 4-point semiquantitative scale by two

Table 1 Demographic and clinical features of the patients in the two cohorts

\begin{tabular}{lllll}
\hline & Cohort 1 & \multicolumn{3}{l}{ Cohort 2 } \\
\cline { 2 - 5 } & $\begin{array}{l}\text { SpA } \\
(\boldsymbol{n}=\mathbf{1 8})\end{array}$ & $\begin{array}{l}\text { RA } \\
(\boldsymbol{n}=\mathbf{2 0})\end{array}$ & $\begin{array}{l}\text { SpA } \\
(\boldsymbol{n}=\mathbf{1 1})\end{array}$ & $\begin{array}{l}\text { RA } \\
(\boldsymbol{n}=\mathbf{8})\end{array}$ \\
\hline Gender, \% female & 40 & 58 & 33 & 100 \\
\hline Age, years & $47(33-55)$ & $62(53-74)$ & $38(31-44)$ & $48(32-63)$ \\
\hline Disease duration, years & $3(1-29)$ & $3(1-11)$ & $2(1-4)$ & $2(1-5)$ \\
\hline Swollen-joint count & $1(1-2)$ & $8(5-15)$ & $1(0-1)$ & $1(0-2)$ \\
\hline CRP, mg/L & $12(5-31)$ & $19(8-58)$ & $2(1-7)$ & $5(4-11)$ \\
\hline ESR, mm/hour & $29(23-43)$ & $47(33-66)$ & $2(2-16)$ & $21(13-29)$ \\
\hline$\%$ using DMARDs & 80 & 54 & 50 & 100
\end{tabular}

As described in Materials and methods, synovial tissue biopsies were obtained from patients with spondyloarthritis (SpA) and rheumatoid arthritis (RA) (Cohort 1). Monocytes were isolated from peripheral blood of SpA and RA patients (Cohort 2). Except when indicated otherwise, values are expressed as the median (interquartile range). CRP, C-reactive protein; DMARD, diseasemodifying anti-rheumatic drug; ESR, erythrocyte sedimentation rate. 
independent observers (CAA, TN), as described previously [5].

\section{Monocyte isolation and in vitro polarization}

Monocytes were isolated from peripheral blood with gradient centrifugation with Lymphoprep (Axis-Shield PoPAS, Oslo, Norway) and, subsequently, Percoll gradient separation (GE Healthcare, Uppsala, Sweden). Monocytes were analyzed immediately with flow cytometry or cultured at a concentration of $0.5 \times 10^{6} / \mathrm{ml}$ in Iscove Modified Dulbecco Medium (IMDM) (Invitrogen, Breda, The Netherlands) supplemented with $10 \%$ fetal calf serum (FCS) (PAA Laboratories, Cölbe, Germany). Cultured monocytes were polarized in vitro with human recombinant IFN- $\gamma(10 \mathrm{ng} / \mathrm{ml}$; R\&D Systems, Abingdon, UK), IL-4 (10 ng/ml; Miltenyi Biotec, Bergisch Gladbach, Germany), or IL-10 (10 ng/ml; R\&D Systems) for 4 days. For further analysis, polarized macrophages were recovered by scraping of the culture plate.

\section{Flow cytometry}

Surface-marker expression on monocytes and in vitro polarized macrophages was analyzed with flow cytometry (BD FACS Calibur Flow Cytometer, Erembodegem, Belgium) by using fluorochrome-labeled monoclonal antibodies against CD80 (clone L307.4; BD Pharmingen, Breda, the Netherlands), CD64 (clone 10.1; BioLegend), CD200R (clone OX108; AbD Serotec), CD14 (clone 61D3; eBioscience, San Diego, CA, USA), CD163 (clone GHI/61; BD Pharmingen), and CD16 (clone DJ130c; AbD Serotec, Düsseldorf, Germany). Equivalent amounts of isotype-matched control antibodies were included in all experiments as negative controls. Before staining, Fc receptors were blocked with 10\% human serum (Lonza, Cologne, Germany). Data were analyzed with Flow Jo Flow Cytometry Analysis software (Tree Star, Ashland, OR, USA) after gating on the myeloid population in the $\mathrm{FSC} / \mathrm{SSC}$ window. Values were expressed as the ratio of the geometric mean fluorescence intensity (gMFI) of the marker of interest over the gMFI of the isotype control.

\section{Double immunofluorescence}

Frozen synovial tissue sections were fixed in acetone and blocked with 10\% goat serum (Dako, Glostrup, Denmark), followed by incubation with Biotin blocking system (Dako). Mouse monoclonal antibodies against CD80 (clone 2D10; BioLegend, Uithoorn, The Netherlands), CD64 (clone 10.1; BioLegend), CD200R (clone OX108; AbD Serotec, Düsseldorf, Germany), CD14 (clone TUK4; Dako), CD163 (clone 5cFAT; BMA Biomedicals, Augst, Switzerland), CD16 (clone HI16a; Abbiotec, San Diego, CA, USA), and CD32 (clone AT10; abcam, Cambridge, UK) were added, followed by incubation with Alexa-555-conjugated goat anti-mouse antibody (Molecular Probes Europe, Leiden, The Netherlands). After blocking with 10\% mouse serum (Dako), the sections were incubated with biotinylated mouse monoclonal antibodies against CD68 (clone Y1/82A; BioLegend), CD64 (clone 10.1; BioLegend), CD200R (clone OX108; AbD Serotec), and CD163 (clone GHI/ 61; BioLegend). After incubation with streptavidin-Alexa 488 (Molecular Probes Europe, Leiden, The Netherlands), the slides were mounted with Vectashield containing DAPI (Vector Laboratories, Burlingame, CA, USA) and analyzed on a fluorescent imaging microscope (Leica DMRA, Wetzlar, Germany) coupled to a chargecoupled device (CCD) camera and Image-Pro Plus software (Media Cybernetics, Dutch Vision Components, Breda, The Netherlands). To quantify the coexpression of CD68 with CD64, CD200R, CD14, and CD163, the number of positively stained cells was counted in a minimum of five microscopic fields, and the percentage of double-positive cells from the total number of CD68positive cells was calculated.

\section{Statistics}

Statistical analysis was performed by using Prism software (GraphPad, La Jolla, CA, USA). Data were expressed as median \pm interquartile range. A MannWhitney test was used for comparisons between two groups (SpA compared with RA) and ANOVA followed by a Bonferroni posttest was used for comparisons among more than two groups. A $P$ value of less than 0.05 was considered statistically significant.

\section{Results}

The expression of CD163 but not other M2 phenotypic markers is increased on intimal lining layer macrophages in $\mathrm{SpA}$ versus $\mathrm{RA}$ synovitis

To confirm and extend our previous description of increased CD163 expression in SpA compared with RA synovitis [3,22-25], we performed a detailed histologic analysis of the recently described panel of phenotypic markers for $M \Phi_{\text {IFN- } \gamma}, M \Phi_{\text {IL-4 }}$, and $M \Phi_{\text {IL-10 }}$ [21]. As previously shown, the number of $\mathrm{CD} 68^{+}$macrophages in the intimal lining layer and synovial sublining was similar between the two diseases (Figure 1A, D), whereas CD163 expression was higher in the SpA compared with the RA intimal lining layer $(P<0.05)$ (Figure $1 \mathrm{~B})$, but similar in the synovial sublining (Figure 1E). However, the expression of another $M \Phi_{\mathrm{IL}-10}$ marker, CD32, was similar in both diseases, for both the intimal lining layer and the synovial sublining (Figure 1C, F). The expression of the $M \Phi_{\mathrm{IFN}-\gamma}$ marker CD64, the positive $\mathrm{M} \Phi_{\mathrm{IL}-4}$ marker CD200R, and the negative $\mathrm{M} \Phi_{\mathrm{IL}-4}$ marker CD14 was similar in the synovial sublining of SpA and RA (Figure 1G through $1 \mathrm{I}$ ) and was very low to absent in the intimal lining layer (data not shown). 


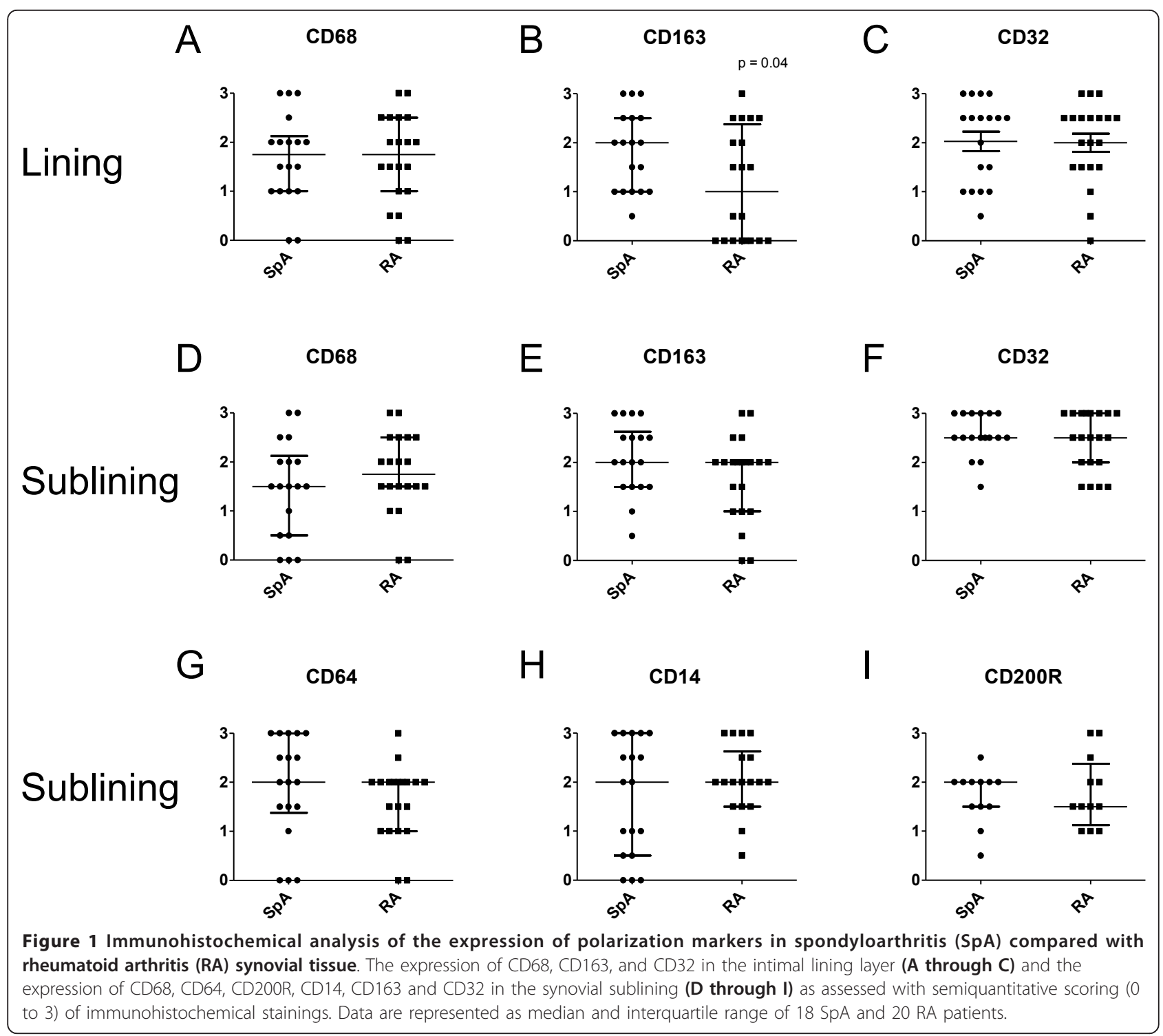

These histologic data confirmed the higher CD163 expression in SpA compared with RA synovitis, but failed to provide additional evidence for a biased M2 polarization in SpA.

The phenotype of peripheral blood monocytes is similar in SpA and RA

To investigate whether the increased expression of CD163 in SpA synovitis is related to preferential $M \Phi_{\mathrm{IL}-}$ 10 polarization, we set up a series of additional experiments. Because monocytes from peripheral blood of SpA patients display a defective IFN- $\gamma$ signature [28] and IFN- $\gamma$ is the prototypic M1 polarizing cytokine, we first assessed whether not only intimal lining layer macrophages, but also peripheral blood monocytes have a distinct phenotype in SpA. We quantified the percentage of classic $\mathrm{CD} 14^{+} \mathrm{CD} 16^{-}$monocytes, intermediate $\mathrm{CD} 14^{+} \mathrm{CD} 16^{+}$monocytes, and nonclassic CD14 ${ }^{\text {dim }} \mathrm{CD} 16^{+}$monocytes [32] in peripheral blood from SpA and RA patients and healthy donors, and did not observe differences in these monocyte subsets between the groups (Figure 2A). We next assessed the expression of macrophage polarization markers on CD $14^{+}$monocytes and measured a marked expression of the $M \Phi_{\text {IFN- } \gamma}$ marker CD64 and a more modest expression of the $M \Phi_{\mathrm{IL}-4}$ marker CD200R and the $\mathrm{M} \Phi_{\mathrm{IL}-10}$ marker CD16 (Figure 2B-D). However, no differences were found in the expression of these markers between SpA and RA patients and healthy controls. Expression of $M \Phi_{\text {IFN- } \gamma}$ marker CD80 and $M \Phi_{\text {IL-10 }}$ marker CD163 on monocytes was very low (data not shown). Based on this assessment, no indication exists 


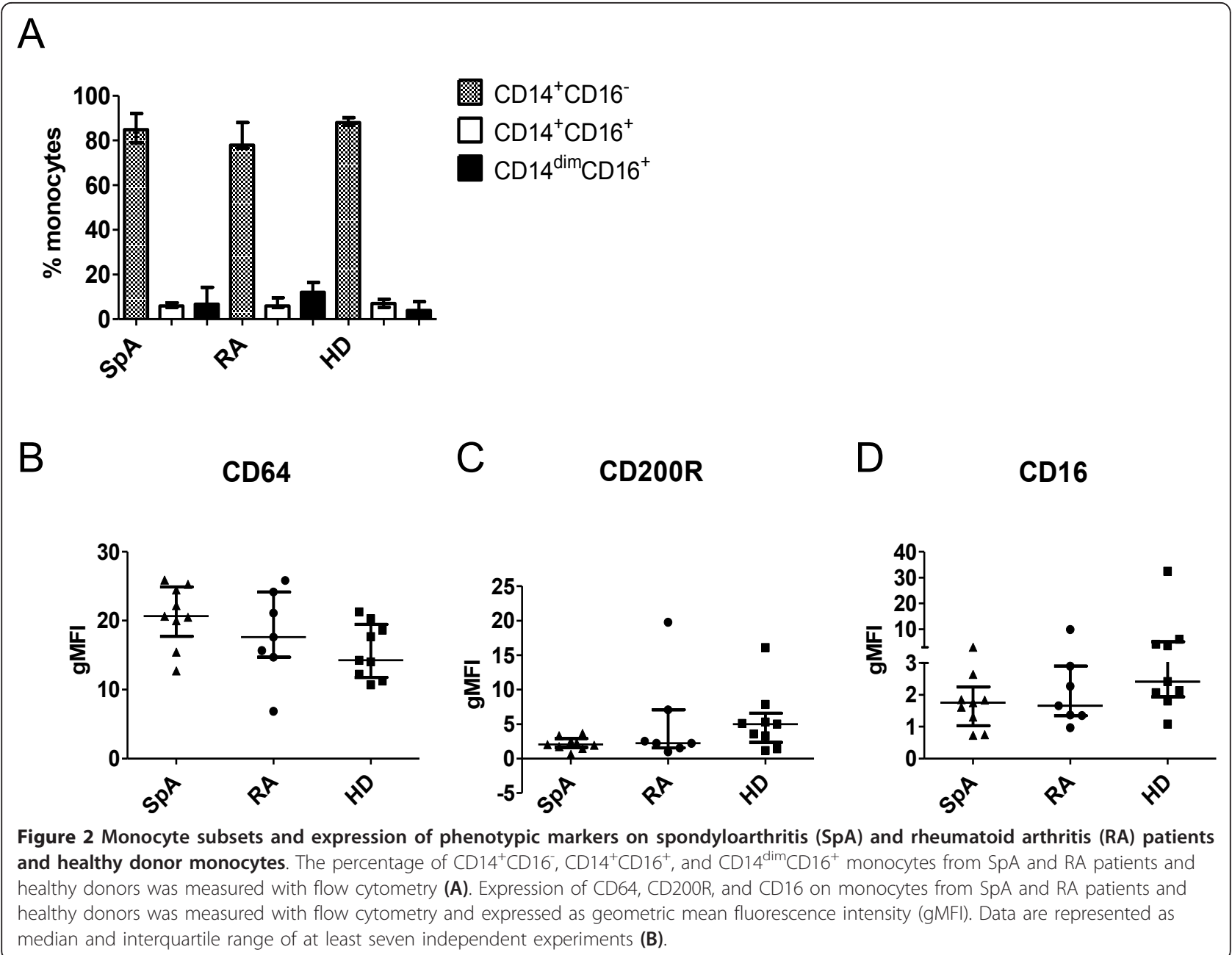

of phenotypic differences between monocytes from SpA and RA patients and healthy individuals.

The phenotype of in vitro polarized monocyte-derived macrophages is similar in SpA and RA

Further to investigate the propensity of monocytes to polarize preferentially toward a specific macrophage subset in SpA, monocytes from SpA and RA patients and healthy donors were polarized in vitro in the presence of IFN- $\gamma$, IL-4, or IL-10. The expression of specific phenotypic markers was measured with flow cytometry after 4 days of polarization. On spontaneous macrophage maturation in the absence of polarizing cytokines, no differences were noted in the expression of phenotypic markers between SpA and RA patients and healthy donors (data not shown). As previously described in healthy donors [21], IFN- $\gamma$ specifically upregulated the membrane expression of CD80 and CD64, IL-4 upregulated CD200R and downregulated CD14, whereas IL-10 upregulated CD163 and CD16. After polarization of patient and healthy donor monocytes, we measured a similar modulation of these phenotypic markers in all three groups (Figure 3). In conclusion, we found no evidence for differences in the polarization potential of monocyte-derived macrophages from SpA and RA patients and healthy individuals.

Intimal lining layer macrophages display a $M \Phi_{\mathrm{IL}-10}$-like phenotype

Because we observed an increased expression of CD163, but no differences in the expression of other polarization markers in SpA compared with RA synovitis, we next performed double-immunofluorescence staining to characterize further the polarization phenotype of synovial macrophages. We studied the colocalization of panmacrophage marker CD68 with $M \Phi_{\text {IFN- } \gamma}$ marker CD64 (Figure 4A), $M \Phi_{\mathrm{IL}-4}$ markers CD200R and CD14 (Figure $4 \mathrm{~B}, \mathrm{C}$ ), and $\mathrm{M} \Phi_{\mathrm{IL}-10}$ markers CD163, CD16, and CD32 (Figure 4D-F). Intimal lining layer $\mathrm{CD}^{+} 8^{+}$cells highly expressed the $M \Phi_{\mathrm{IL}-10}$ markers CD163 and CD32 (Figure $4 \mathrm{D}, \mathrm{F})$, whereas the expression of CD64, CD80, CD200R, CD14, and CD16 was almost absent (Figure 


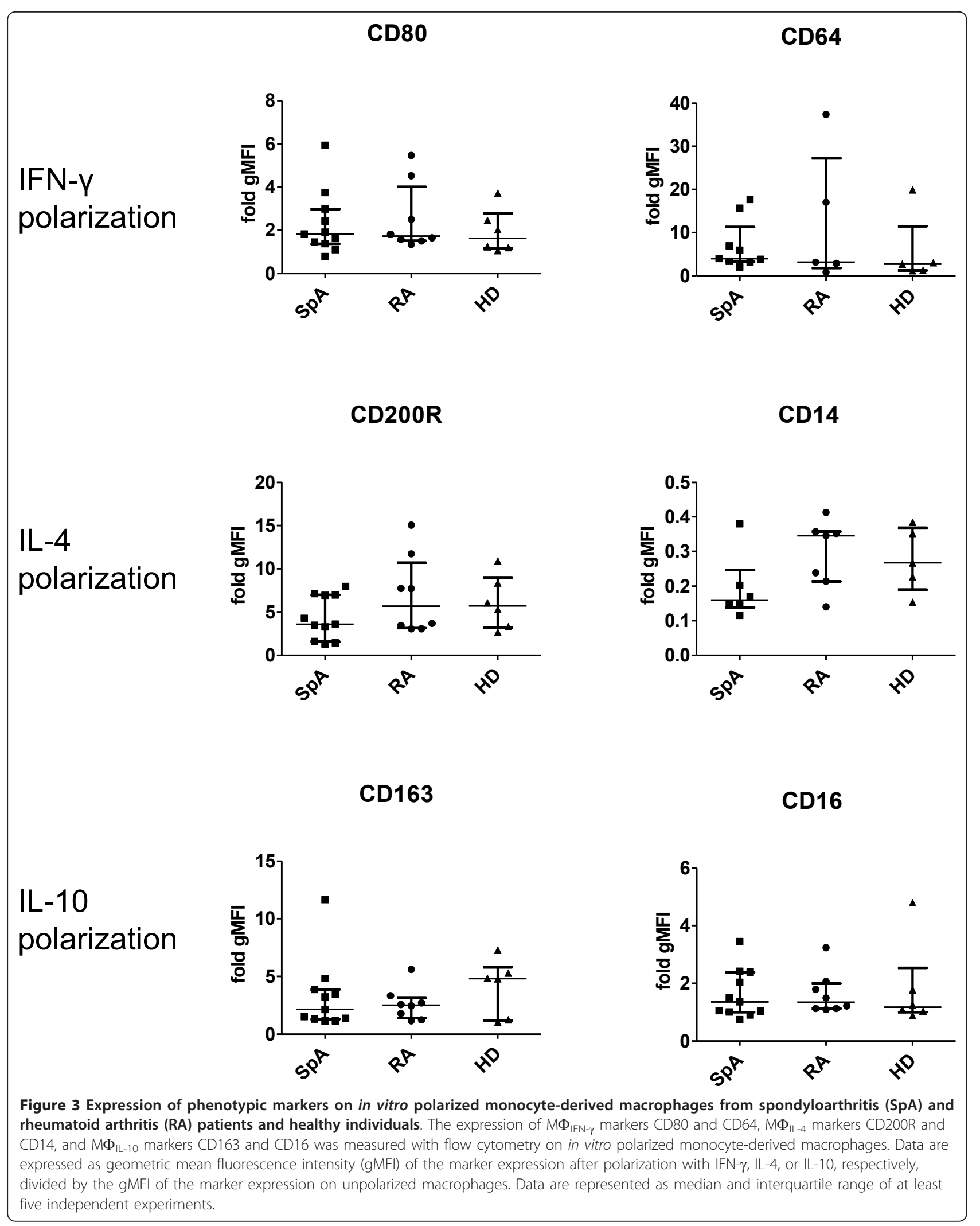




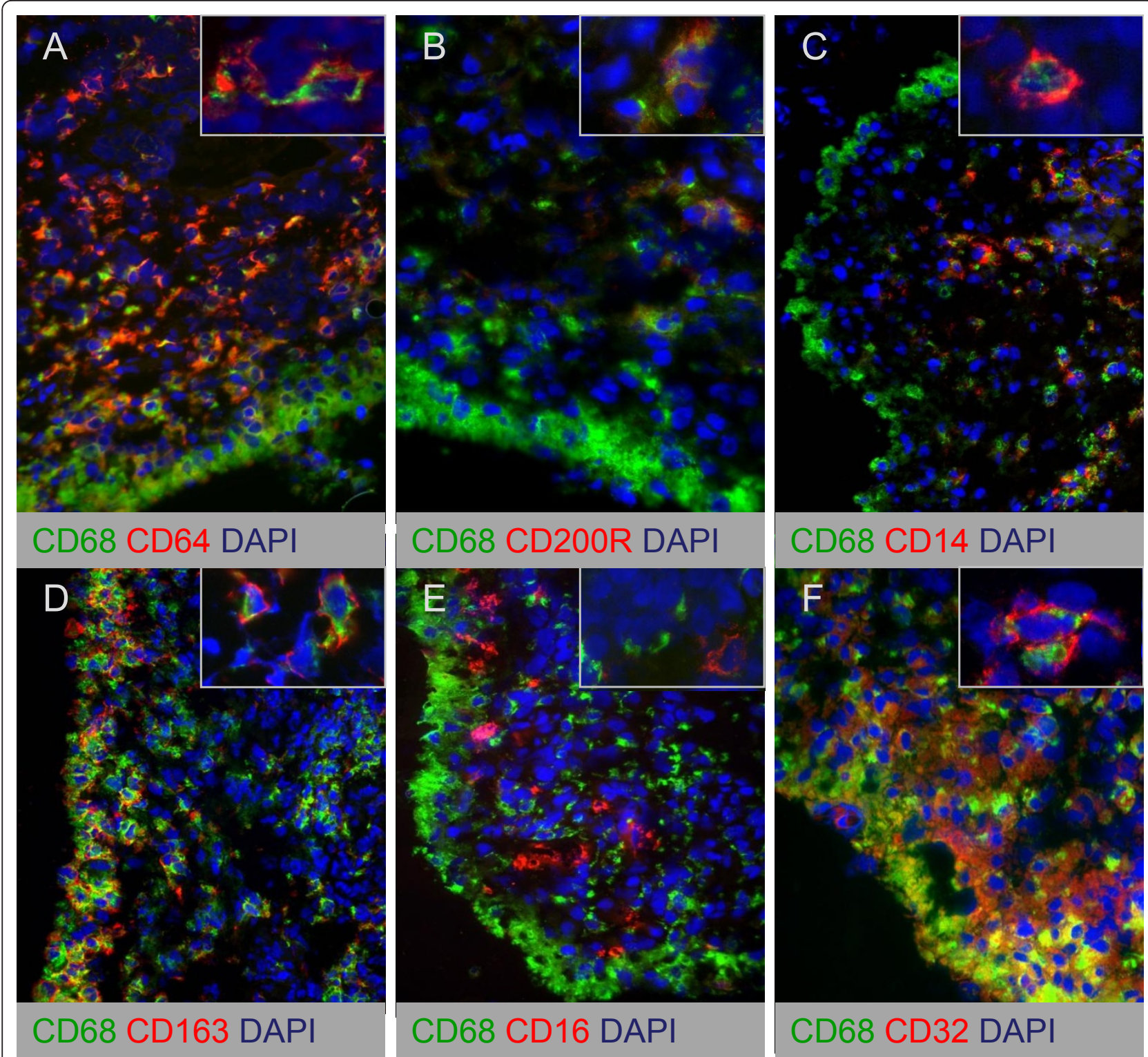

Figure 4 Double immunofluorescence stainings of CD68 and macrophage polarization markers on synovial tissue from chronic

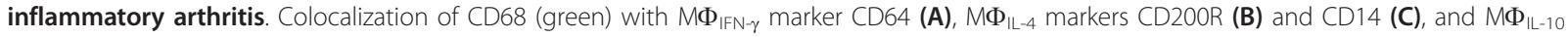
markers CD163 (D), CD16 (E), and CD32 (F) (red) on synovial tissue macrophages. Figures are representative of five spondyloarthritis (SpA) and five rheumatoid arthritis (RA) patients. Higher-magnification photos are included in each figure part.

4A-C, 4E) in both SpA and RA. In contrast, synovial sublining macrophages abundantly expressed both the $M \Phi_{\mathrm{IL}-10}$ markers CD163 and CD32 (Figure 4D, F) and the $M \Phi_{\text {IFN- } \gamma}$ marker CD64 (Figure 4A). The positive $M \Phi_{\mathrm{IL}-4}$ marker CD200R showed a low expression and low colocalization with CD68 (Figure 4B), whereas the negative $M \Phi_{\mathrm{IL}-4}$ marker CD14 strongly colocalized with CD68 (Figure 4C). In agreement with previous reports, CD80 expression was almost absent in synovial tissue (data not shown) [33], whereas CD16 expression was low on $\mathrm{CD}^{+} 8^{+}$cells (Figure 4E). Although the number of samples used in these double-immunofluorescence experiments is too small for an accurate statistical analysis, quantification of the staining confirmed the lack of marked differences in the expression of these markers between SpA and RA synovial sublining macrophages (Figure 5). These findings suggest an $\mathrm{M} \Phi_{\mathrm{IL}-10}$-like phenotype of intimal lining layer macrophages in both SpA and RA, whereas synovial sublining macrophages had a more heterogeneous phenotype. 


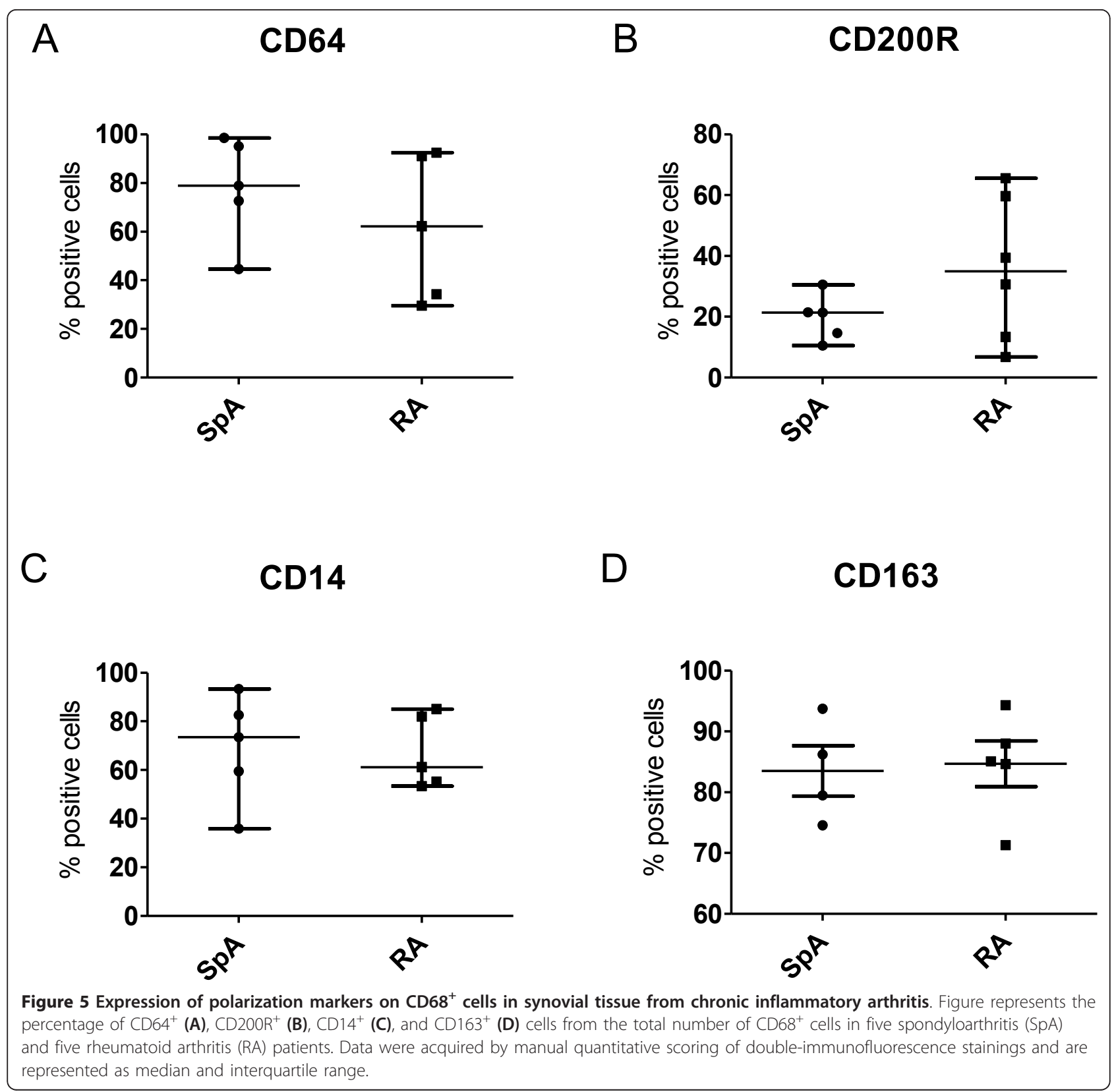

Synovial sublining macrophages co-express $M \Phi_{\text {INF- } \gamma}$ and $\mathbf{M} \Phi_{\mathrm{IL}-10}$ markers

To characterize further the phenotype of synovial sublining macrophages, we studied the colocalization of $M \Phi_{\text {IFN- } \gamma}$ marker CD64 with CD200R, CD163, and CD32 (Figure 6A-C), colocalization of $\mathrm{M \Phi}_{\mathrm{IL}-4}$ marker CD200R with CD14, CD163, and CD32 (Figure 6D-F), and colocalization of $M \Phi_{\mathrm{IL}-10}$ marker CD163 with CD14 and CD32 (Figure 6G, H). These stainings confirmed that both $M \Phi_{\mathrm{IL}-10}$ markers CD163 and CD32 were expressed on the same cells in SpA and RA synovitis (Figure 6H). However, we also observed a high degree of coexpression between the $M \Phi_{\mathrm{INF}-\gamma}$ marker CD64 and the $M \Phi_{\mathrm{IL}-}$
10 markers CD163 and CD32 (Figure 6B, C). Furthermore, the smaller macrophage subset that expressed the $\mathrm{M} \Phi_{\mathrm{IL}-4}$ marker CD200R also appeared to coexpress CD64, CD14, CD163, and CD32 (Figure 6D-F). Taken together, these data indicate that synovial sublining macrophages display a mixed $M \Phi_{\mathrm{INF}-\gamma} / \mathrm{M} \Phi_{\mathrm{IL}-10}$ phenotype. Within this population, a smaller macrophage subset also coexpresses the $\mathrm{M} \Phi_{\mathrm{IL}-4}$ marker CD200R.

\section{Discussion}

Synovial tissue macrophages play a key role in chronic inflammatory arthritis, but the distribution and the function of different macrophage subsets in this process 

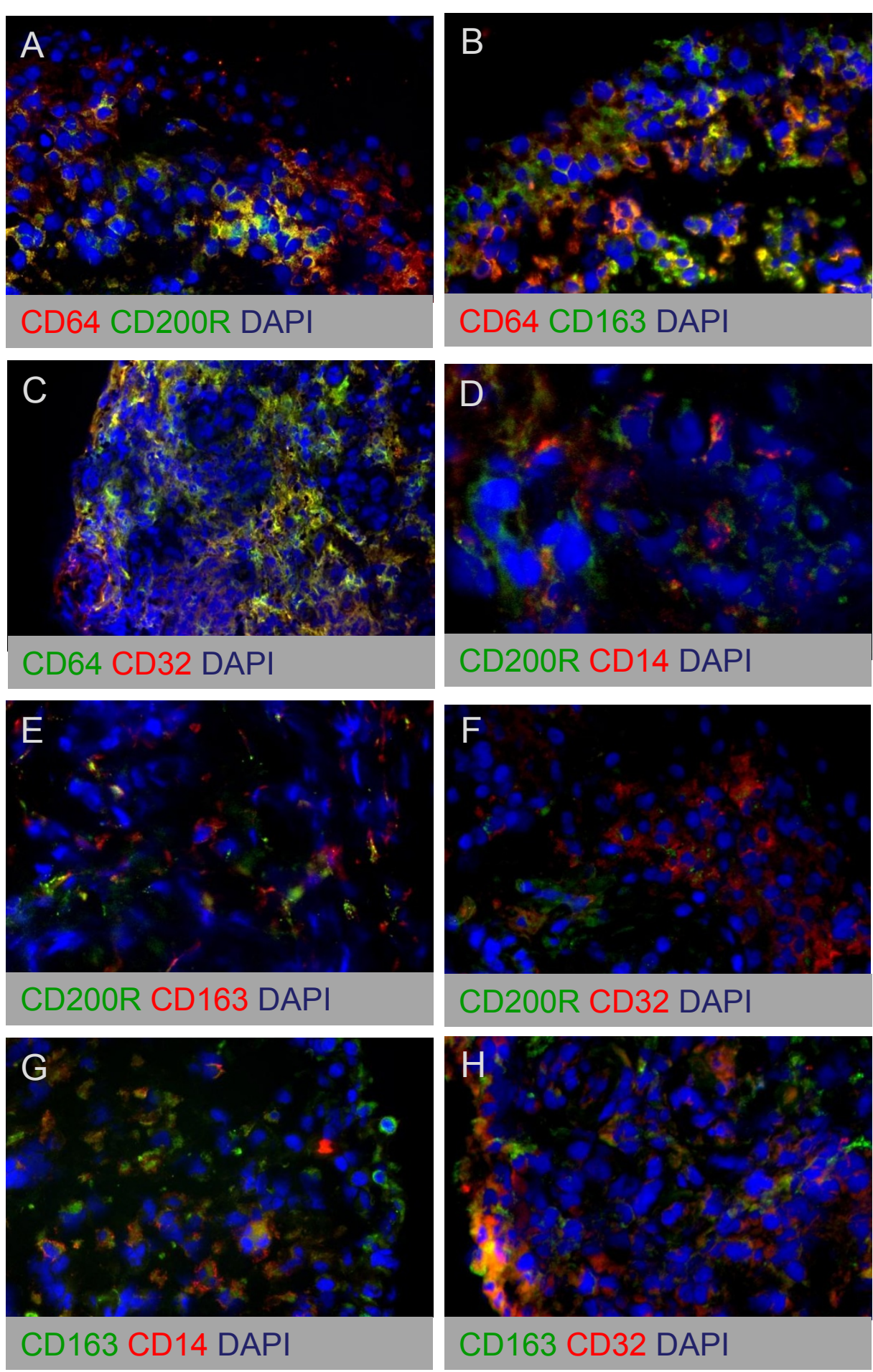

Figure 6 Double-immunofluorescence stainings of $M \Phi_{\mathrm{IFN}-\gamma}, M \Phi_{\mathrm{IL}-4}$, and $M \Phi_{\mathrm{IL}-10}$ polarization markers on synovial tissue from chronic inflammatory arthritis. Colocalization of $M \Phi_{\mid F N-\gamma}$ marker CD64 with CD200R (A), CD163 (B), and CD32 (C), colocalization of $M \Phi_{\| L-4}$ marker CD200R with CD14 (D), CD163 (E), and CD32 (F), and colocalization of M $\Phi_{\mathrm{IL}-10}$ marker CD163 with CD14 (G) and CD32 (H). Figure parts are representative of five spondyloarthritis (SPA) and five rheumatoid arthritis (RA) patients. 
remain largely unknown. Based on the increased CD163 expression in SpA synovitis [3,22-25], we proposed the hypothesis of a preferential M2 polarization in SpA, as opposed to an M1 polarization in RA [27]. The present study aimed to assess this hypothesis experimentally by a detailed characterization of macrophages in inflammatory arthritis, by using a recently validated panel of phenotypic markers for in vitro polarized human macrophage subsets [21]. Comparison of macrophage phenotypic marker expression between SpA and RA synovitis confirmed the higher expression of CD163 in the SpA intimal lining layer. Although previous reports showed increased CD163 expression in both the intimal lining layer and synovial sublining, the differences appeared to be larger in the intimal lining layer [3,22].

As CD163 is a prototypical marker for $\mathrm{M} \Phi_{\mathrm{IL}-10}$, we performed three types of experiments to assess whether the increased CD163 expression reflected a preferential M2 polarization in SpA. First, the previously described inverse IFN- $\gamma$ signature in monocytes from SpA patients [28] suggested that even before entering the synovial compartment, myeloid cells may be skewed to polarize toward M2 rather than M1. Our analysis of peripheral blood monocytes, however, did not reveal phenotypic differences between SpA, RA, and healthy controls. In humans, three monocyte subsets have been identified: classic $\mathrm{CD} 14^{+} \mathrm{CD} 16^{-}$, intermediate $\mathrm{CD} 14^{+} \mathrm{CD} 16^{+}$, and nonclassic $\mathrm{CD} 14^{\mathrm{dim}} \mathrm{CD} 16^{+}$monocytes. Among these subsets, $\mathrm{CD} 14^{+} \mathrm{CD} 16^{+}$monocytes were described to be recruited in tissues during inflammation and to produce high amounts of TNF [32,34-37]. Although other publications report contrasting findings of either an increased [38-40] or a decreased [41] percentage of $\mathrm{CD} 14^{+} \mathrm{CD} 16^{+}$ monocytes in inflammatory compared with healthy conditions, our experiments did not identify differences in these monocyte subsets between SpA and RA patients and healthy donors. Additionally, we did not observe differential expression of other phenotypic markers, such as CD64, CD16, and CD32, whereas the expression of CD80 and CD163 was very low on peripheral monocytes, as previously described $[42,43]$.

Second, we assessed whether a potential bias toward M2 may appear during the differentiation of monocytes toward macrophages. In vitro polarization experiments with monocyte-derived macrophages failed, however, to indicate preferential polarization to a distinct subset in SpA compared with RA patients and healthy donors. These data suggest that the $\mathrm{CD} 163^{+}$macrophage phenotype in SpA synovitis is determined by the local inflammatory milieu rather than by intrinsic myeloid alterations. Previous publications showing CD163 upregulation during in vitro macrophage maturation in the presence of SpA synovial fluid [27] and a strong synovial
CD163 downregulation on effective antiinflammatory treatment $[12,13]$ support this observation.

Third, we assessed whether the local upregulation of CD163 on intimal lining layer macrophages in SpA was associated with differential expression of other phenotypic polarization markers between SpA and RA. This was not the case, as, for example, both the $M \Phi_{\mathrm{IL}-10}$ marker CD32 and the prototypical $M \Phi_{\mathrm{IFN}-\gamma}$ marker CD64 were similarly expressed in both diseases. These data question whether the altered expression of CD163, which is a reliable M2 marker in vitro, necessarily reflects a marked M2 versus M1 polarization in vivo. Supporting the notion that the phenotype of macrophage subsets in vivo is more complex than the conceptual in vitro framework of M1 and M2, detailed doublestaining analysis showed that synovial sublining macrophages display a mixed phenotypic profile with a high colocalization of $M \Phi_{\mathrm{IFN}-\gamma}$ and $\mathrm{M} \Phi_{\mathrm{IL}-10}$ markers. Similar observations of mixed polarization profiles were already described for human adipose tissue macrophages (ATMs), which show features of both alternative (CD206, CD163, IL-10, TGF- $\beta$ ) and classic (TNF, IL-6, IL-23, IL-8) activation $[44,45]$. An important question raised by this in vivo complexity is whether these cells exert both the pro- and antiinflammatory functions, which have been attributed to M1 and M2 macrophages, respectively, or whether they are steady-state cells waiting for additional signals to determine their ultimate phenotype and function. The latter hypothesis implies a large plasticity of tissue macrophages, as previously suggested in tumor environment [46], adipose tissue [47], and atherosclerosis [48]. Tumor-associated macrophages were described to have M2 properties, with low inflammatory chemokine receptors, poor antigen presentation, high IL-10, and low IL-12 production [49-53]. Interestingly, polarization toward an M1-like phenotype was shown to suppress tumor progression [54]. Adipose tissue macrophages were also reported to switch from an M2-like phenotype in normal adipose tissue to an M1-like phenotype in diet-induced obesity $[55,56]$, but reports exist of a predominant M2 activation in insulin resistance and obesity [57]. The same holds true for the macrophages in the vascular wall, which were described to switch from an M2- to an M1like phenotype and become so-called foam cells [58-60], whereas other authors describe an accumulation of M2like cells in the atherosclerotic plaque [61]. Although the interpretation of these studies remains difficult in the absence of single markers that can unequivocally discriminate between macrophage subsets in vivo [15], the macrophage phenotype in the synovial sublining may reflect the same plasticity as in tumors, fat tissue, and atherosclerosis. 
In contrast with the mixed phenotype of synovial sublining macrophages, the intimal lining layer macrophages clearly displayed an $M \Phi_{\mathrm{IL}-10}$-like phenotype. We observed the same differences between the phenotype of intimal lining layer and synovial sublining macrophages, not only in SpA and RA but also in gout synovitis (data not shown), suggesting that this macrophage distribution pattern is a global feature of synovial inflammation. Together with the low expression of CD14 in the intimal lining layer, this observation may fit a model according to which the intimal lining layer contains mainly mature resident macrophages, whereas the synovial sublining is actively infiltrated with immature monocyte-derived macrophages. This model is in agreement with publications showing that the number of synovial sublining but not intimal lining layer macrophages is associated with disease activity in RA and correlates with response to therapy [7-9].

Concerning the differences between SpA and RA, this model would predict that the synovial sublining is similarly infiltrated by monocyte-derived macrophages with a mixed phenotype in both pathologies. However, the $\mathrm{MRP} 8 / 14^{+}$infiltrating macrophages were shown to accumulate highly in the intimal lining layer in RA [3] and secrete a variety of proinflammatory mediators [62]. In contrast, the SpA intimal lining layer appears to consist mainly of resident, $M \Phi_{\mathrm{IL}-10}$-like macrophages, which is in accordance with the lower levels of M1-derived cytokines in SpA compared with RA synovial fluid [27] and with the less-destructive appearance of SpA synovitis.

Based on these findings, modulating the polarization and/or the migration of distinct macrophage subsets to the intimal lining layer would represent interesting therapeutic approaches for chronic synovitis.

\section{Abbreviations}

CD32: cluster of differentiation 32; CD163: cluster of differentiation 163; FCS: fetal calf serum; gMFI: geometric mean fluorescence intensity; IMDM: Iscove Modified Dulbecco Medium; RA: rheumatoid arthritis; SpA: spondyloarthritis.

\section{Acknowledgements}

DB is supported by a VIDI grant from The Netherlands Organization for Scientific Research (NWO) and by a grant from the Dutch Arthritis Foundation (Reumafonds).

\section{Author details \\ 'Department of Clinical Immunology and Rheumatology, Academic Medical Center/University of Amsterdam, Meibergdreef 9, 1105 AZ Amsterdam, The Netherlands. ${ }^{2}$ Department of Experimental Immunology, University of Amsterdam, Meibergdreef 9, 1105 AZ Amsterdam, The Netherlands. ${ }^{3}$ GlaxoSmithKline, Gunnels Wood Road, Stevenage Herts, SG1 2NY, UK.}

\section{Authors' contributions}

CAA, PPT, and DLPB participated in the design of the study. Acquisition of the data was performed by CAA, TN, and MJH. Data were analyzed and interpreted by CAA and TN. The manuscript was drafted by CAA and was revised by MJH, PPT, and DLPB. All authors read and approved the final manuscript.

\section{Competing interests}

The authors declare that they have no competing interests.

Received: 27 February 2012 Revised: 23 March 2012

Accepted: 11 April 2012 Published: 11 April 2012

\section{References}

1. Smith MD, Barg E, Weedon H, Papengelis V, Smeets T, Tak PP, Kraan M, Coleman M, Ahern MJ: Microarchitecture and protective mechanisms in synovial tissue from clinically and arthroscopically normal knee joints. Ann Rheum Dis 2003, 62:303-307.

2. Tak PP, Smeets TJ, Daha MR, Kluin PM, Meijers KA, Brand R, Meinders AE, Breedveld FC: Analysis of the synovial cell infiltrate in early rheumatoid synovial tissue in relation to local disease activity. Arthritis Rheum 1997, 40:217-225.

3. De Rycke L, Baeten D, Foell D, Kruithof E, Veys EM, Roth J, De KF: Differential expression and response to anti-TNFalpha treatment of infiltrating versus resident tissue macrophage subsets in autoimmune arthritis. J Pathol 2005, 206:17-27.

4. Tak PP, Bresnihan B: The pathogenesis and prevention of joint damage in rheumatoid arthritis: advances from synovial biopsy and tissue analysis. Arthritis Rheum 2000, 43:2619-2633.

5. Baeten D, Kruithof E, De RL, Boots AM, Mielants H, Veys EM, De KF: Infiltration of the synovial membrane with macrophage subsets and polymorphonuclear cells reflects global disease activity in spondyloarthropathy. Arthritis Res Ther 2005, 7:R359-R369.

6. Baeten D, Houbiers J, Kruithof E, Vandooren B, Van den Bosch F, Boots AM, Veys EM, Miltenburg AM, De KF: Synovial inflammation does not change in the absence of effective treatment: implications for the use of synovial histopathology as biomarker in early phase clinical trials in rheumatoid arthritis. Ann Rheum Dis 2006, 65:990-997.

7. Gerlag DM, Haringman JJ, Smeets TJ, Zwinderman AH, Kraan MC, Laud PJ, Morgan S, Nash AF, Tak PP: Effects of oral prednisolone on biomarkers in synovial tissue and clinical improvement in rheumatoid arthritis. Arthritis Rheum 2004, 50:3783-3791.

8. Haringman JJ, Gerlag DM, Zwinderman AH, Smeets TJ, Kraan MC, Baeten D, Mclnnes IB, Bresnihan B, Tak PP: Synovial tissue macrophages: a sensitive biomarker for response to treatment in patients with rheumatoid arthritis. Ann Rheum Dis 2005, 64:834-838.

9. Wijbrandts CA, Vergunst CE, Haringman JJ, Gerlag DM, Smeets TJ, Tak PP: Absence of changes in the number of synovial sublining macrophages after ineffective treatment for rheumatoid arthritis: implications for use of synovial sublining macrophages as a biomarker. Arthritis Rheum 2007, 56:3869-3871.

10. Baeten D, Kruithof E, Van den Bosch F, Demetter P, Van DN, Cuvelier C, De VM, Mielants H, Veys EM, De KF: Immunomodulatory effects of antitumor necrosis factor alpha therapy on synovium in spondylarthropathy: histologic findings in eight patients from an open-label pilot study. Arthritis Rheum 2001, 44:186-195.

11. Canete JD, Celis R, Hernandez V, Pablos JL, Sanmarti R: Synovial immunopathological changes associated with successful abatacept therapy in a case of severe refractory psoriatic arthritis. Ann Rheum Dis 2010, 69:935-936.

12. Kruithof E, De RL, Roth J, Mielants H, Van den Bosch F, De KF, Veys EM, Baeten D: Immunomodulatory effects of etanercept on peripheral joint synovitis in the spondyloarthropathies. Arthritis Rheum 2005, 52:3898-3909.

13. Kruithof E, Baeten D, Van den Bosch F, Mielants H, Veys EM, De KF: Histological evidence that infliximab treatment leads to downregulation of inflammation and tissue remodelling of the synovial membrane in spondyloarthropathy. Ann Rheum Dis 2005, 64:529-536.

14. van Lent $P L$, Holthuysen $A E$, Van $R N$, Van De Putte $L B$, van den Berg WB: Local removal of phagocytic synovial lining cells by clodronateliposomes decreases cartilage destruction during collagen type II arthritis. Ann Rheum Dis 1998, 57:408-413.

15. Murray PJ, Wynn TA: Protective and pathogenic functions of macrophage subsets. Nat Rev Immunol 2011, 11:723-737.

16. Hamilton JA, Tak PP: The dynamics of macrophage lineage populations in inflammatory and autoimmune diseases. Arthritis Rheum 2009, 60:1210-1221. 
17. Stein M, Keshav S, Harris N, Gordon S: Interleukin 4 potently enhances murine macrophage mannose receptor activity: a marker of alternative immunologic macrophage activation. J Exp Med 1992, 176:287-292.

18. Gordon S: Alternative activation of macrophages. Nat Rev Immunol 2003, 3:23-35.

19. Mantovani A, Sica A, Sozzani S, Allavena P, Vecchi A, Locati M: The chemokine system in diverse forms of macrophage activation and polarization. Trends Immunol 2004, 25:677-686.

20. Mosser DM, Edwards JP: Exploring the full spectrum of macrophage activation. Nat Rev Immunol 2008, 8:958-969.

21. Ambarus CA, Krausz S, van EM, Hamann J, Radstake TR, Reedquist KA, Tak PP, Baeten DL: Systematic validation of specific phenotypic markers for in vitro polarized human macrophages. J Immunol Methods 2012, 375:196-206.

22. Baeten D, Demetter P, Cuvelier CA, Kruithof E, Van DN, De VM, Veys EM, De KF: Macrophages expressing the scavenger receptor CD163: a link between immune alterations of the gut and synovial inflammation in spondyloarthropathy. J Pathol 2002, 196:343-350.

23. Baeten D, Moller HJ, Delanghe J, Veys EM, Moestrup SK, De KF: Association of $\mathrm{CD}_{163^{+}}$macrophages and local production of soluble CD163 with decreased lymphocyte activation in spondylarthropathy synovitis. Arthritis Rheum 2004, 50:1611-1623.

24. Kruithof E, Baeten D, De RL, Vandooren B, Foell D, Roth J, Canete JD, Boots AM, Veys EM, De KF: Synovial histopathology of psoriatic arthritis, both oligo- and polyarticular, resembles spondyloarthropathy more than it does rheumatoid arthritis. Arthritis Res Ther 2005, 7:R569-R580.

25. Noordenbos T, Yeremenko N, Gofita I, van de Sande M, Tak PP, Canete JD Baeten D: Interleukin-17-positive mast cells contribute to synovial inflammation in spondylarthritis. Arthritis Rheum 2012, 64:99-109.

26. Buechler C, Ritter M, Orso E, Langmann T, Klucken J, Schmitz G: Regulation of scavenger receptor CD163 expression in human monocytes and macrophages by pro- and antiinflammatory stimuli. J Leukoc Biol 2000, 67:97-103.

27. Vandooren B, Noordenbos T, Ambarus C, Krausz S, Cantaert T, Yeremenko N, Boumans M, Lutter R, Tak PP, Baeten D: Absence of a classically activated macrophage cytokine signature in peripheral spondylarthritis, including psoriatic arthritis. Arthritis Rheum 2009, 60:966-975.

28. Smith JA, Barnes MD, Hong D, DeLay ML, Inman RD, Colbert RA: Gene expression analysis of macrophages derived from ankylosing spondylitis patients reveals interferon-gamma dysregulation. Arthritis Rheum 2008, 58:1640-1649

29. van de Sande MG, Gerlag DM, Lodde BM, van Baarsen LG, Alivernini S, Codullo V, Felea I, Vieira-Sousa E, Fearon U, Reece R, Montecucco C, Veale DJ, Pitzalis C, Emery P, Klareskog L, Mclnnes IB, Tak PP: Evaluating antirheumatic treatments using synovial biopsy: a recommendation for standardisation to be used in clinical trials. Ann Rheum Dis 2011, 70:423-427

30. Dougados $M$, van der Linden $S$, Juhlin $R$, Huitfeldt B, Amor B, Calin A, Cats A, Dijkmans B, Olivieri I, Pasero G: The European Spondylarthropathy Study Group preliminary criteria for the classification of spondylarthropathy. Arthritis Rheum 1991, 34:1218-1227.

31. Arnett FC, Edworthy SM, Bloch DA, McShane DJ, Fries JF, Cooper NS, Healey LA, Kaplan SR, Liang MH, Luthra HS: The American Rheumatism Association 1987 revised criteria for the classification of rheumatoid arthritis. Arthritis Rheum 1988, 31:315-324.

32. Cros J, Cagnard N, Woollard K, Patey N, Zhang SY, Senechal B, Puel A, Biswas SK, Moshous D, Picard C, Jais JP, D'Cruz D, Casanova JL, Trouillet C, Geissmann F: Human CD14dim monocytes patrol and sense nucleic acids and viruses via TLR7 and TLR8 receptors. Immunity 2010, 33:375-386.

33. Balsa A, Dixey J, Sansom DM, Maddison PJ, Hall ND: Differential expression of the costimulatory molecules B7.1 (CD80) and B7.2 (CD86) in rheumatoid synovial tissue. Br J Rheumatol 1996, 35:33-37.

34. Belge KU, Dayyani F, Horelt A, Siedlar M, Frankenberger M, Frankenberger B, Espevik T, Ziegler-Heitbrock L: The proinflammatory CD14+CD16+DR++ monocytes are a major source of TNF. J Immunol 2002, 168:3536-3542.

35. Geissmann F, Auffray C, Palframan R, Wirrig C, Ciocca A, Campisi L, NarniMancinelli E, Lauvau G: Blood monocytes: distinct subsets, how they relate to dendritic cells, and their possible roles in the regulation of Tcell responses. Immunol Cell Biol 2008, 86:398-408.
36. Serbina NV, Cherny M, Shi C, Bleau SA, Collins NH, Young JW, Pamer EG: Distinct responses of human monocyte subsets to Aspergillus fumigatus conidia. J Immunol 2009, 183:2678-2687.

37. Ziegler-Heitbrock L: The CD14 ${ }^{+} \mathrm{CD} 16^{+}$blood monocytes: their role in infection and inflammation. J Leukoc Biol 2007, 81:584-592.

38. Blom AB, Radstake TR, Holthuysen AE, Sloetjes AW, Pesman GJ, Sweep FG, van de Loo FA, Joosten LA, Barrera $P$, van Lent $P L$, van den Berg WB: Increased expression of Fcgamma receptors II and III on macrophages of rheumatoid arthritis patients results in higher production of tumor necrosis factor alpha and matrix metalloproteinase. Arthritis Rheum 2003, 48:1002-1014.

39. Kawanaka N, Yamamura M, Aita T, Morita Y, Okamoto A, Kawashima M, Iwahashi M, Ueno A, Ohmoto Y, Makino $\mathrm{H}$ : CD14 ${ }^{+}, \mathrm{CD} 16^{+}$blood monocytes and joint inflammation in rheumatoid arthritis. Arthritis Rheum 2002, 46:2578-2586.

40. Rossol M, Kraus S, Pierer M, Baerwald C, Wagner U: The CD14(bright) CD16 ${ }^{+}$monocyte subset is expanded in rheumatoid arthritis and promotes Th17 expansion. Arthritis Rheum 2012, 64(3):671-7.

41. Cairns AP, Crockard AD, Bell AL: The CD14 ${ }^{+} \mathrm{CD} 16^{+}$monocyte subset in rheumatoid arthritis and systemic lupus erythematosus. Rheumatol Int 2002, 21:189-192.

42. Fleischer J, Soeth E, Reiling N, Grage-Griebenow E, Flad HD, Ernst M: Differential expression and function of CD80 (B7-1) and CD86 (B7-2) on human peripheral blood monocytes. Immunology 1996, 89:592-598.

43. Sanchez C, Domenech N, Vazquez J, Alonso F, Ezquerra A, Dominguez J: The porcine 2A10 antigen is homologous to human CD163 and related to macrophage differentiation. J Immunol 1999, 162:5230-5237.

44. Bourlier V, Zakaroff-Girard A, Miranville A, De BS, Maumus M, Sengenes C, Galitzky J, Lafontan M, Karpe F, Frayn KN, Bouloumie A: Remodeling phenotype of human subcutaneous adipose tissue macrophages. Circulation 2008, 117:806-815

45. Zeyda M, Farmer D, Todoric J, Aszmann O, Speiser M, Gyori G, Zlabinger GJ, Stulnig TM: Human adipose tissue macrophages are of an antiinflammatory phenotype but capable of excessive pro-inflammatory mediator production. Int J Obesity (Lond) 2007, 31:1420-1428.

46. Mantovani A, Germano G, Marchesi F, Locatelli M, Biswas SK: Cancerpromoting tumor-associated macrophages: new vistas and open questions. Eur J Immunol 2011, 41:2522-2525.

47. Odegaard JI, Chawla A: Alternative macrophage activation and metabolism. Annu Rev Pathol 2011, 6:275-297.

48. Wilson HM: Macrophages heterogeneity in atherosclerosis: implications for therapy. J Cell Mol Med 2010, 14:2055-2065.

49. Gocheva V, Wang HW, Gadea BB, Shree T, Hunter KE, Garfall AL, Berman T, Joyce JA: IL-4 induces cathepsin protease activity in tumor-associated macrophages to promote cancer growth and invasion. Genes Dev 2010, 24:241-255.

50. Imtiyaz HZ, Williams EP, Hickey MM, Patel SA, Durham AC, Yuan LJ, Hammond R, Gimotty PA, Keith B, Simon MC: Hypoxia-inducible factor 2alpha regulates macrophage function in mouse models of acute and tumor inflammation. J Clin Invest 2010, 120:2699-2714.

51. Mantovani A, Sozzani S, Locati M, Allavena P, Sica A: Macrophage polarization: tumor-associated macrophages as a paradigm for polarized M2 mononuclear phagocytes. Trends Immunol 2002, 23:549-555.

52. Sierra JR, Corso S, Caione L, Cepero V, Conrotto P, Cignetti A, Piacibello W, Kumanogoh A, Kikutani H, Comoglio PM, Tamagnone L, Giordano S: Tumor angiogenesis and progression are enhanced by Sema4D produced by tumor-associated macrophages. J Exp Med 2008, 205:1673-1685.

53. Steidl C, Lee T, Shah SP, Farinha P, Han G, Nayar T, Delaney A, Jones SJ, lqbal J, Weisenburger DD, Bast MA, Rosenwald A, Muller-Hermelink HK, Rimsza LM, Campo E, Delabie J, Braziel RM, Cook JR, Tubbs RR, Jaffe ES, Lenz G, Connors JM, Staudt LM, Chan WC, Gascoyne RD: Tumor-associated macrophages and survival in classic Hodgkin's lymphoma. N Engl J Med 2010, 362:875-885

54. Duluc D, Corvaisier M, Blanchard S, Catala L, Descamps P, Gamelin E, Ponsoda S, Delneste $Y$, Hebbar M, Jeannin P: Interferon-gamma reverses the immunosuppressive and protumoral properties and prevents the generation of human tumor-associated macrophages. Int J Cancer 2009, 125:367-373.

55. Lumeng CN, Bodzin JL, Saltiel AR: Obesity induces a phenotypic switch in adipose tissue macrophage polarization. J Clin Invest 2007, 117:175-184. 
56. Odegaard Jl, Ricardo-Gonzalez RR, Goforth MH, Morel CR, Subramanian V, Mukundan L, Red EA, Vats D, Brombacher F, Ferrante AW, Chawla A:

Macrophage-specific PPARgamma controls alternative activation and improves insulin resistance. Nature 2007, 447:1116-1120.

57. Spencer M, Yao-Borengasser A, Unal R, Rasouli N, Gurley CM, Zhu B, Peterson CA, Kern PA: Adipose tissue macrophages in insulin-resistant subjects are associated with collagen $\mathrm{VI}$ and fibrosis and demonstrate alternative activation. Am J Physiol Endocrinol Metab 2010, 299 : E1016-E1027.

58. Li AC, Glass CK: The macrophage foam cell as a target for therapeutic intervention. Nat Med 2002, 8:1235-1242.

59. Pinderski $L$, Fischbein MP, Subbanagounder G, Fishbein MC, Kubo N, Cheroutre H, Curtiss LK, Berliner JA, Boisvert WA: Overexpression of interleukin-10 by activated T lymphocytes inhibits atherosclerosis in LDL receptor-deficient mice by altering lymphocyte and macrophage phenotypes. Circ Res 2002, 90:1064-1071.

60. Khallou-Laschet J, Varthaman A, Fornasa G, Compain C, Gaston AT, Clement M, Dussiot M, Levillain O, Graff-Dubois S, Nicoletti A, Caligiuri G: Macrophage plasticity in experimental atherosclerosis. PLoS One 2010, 5 e8852.

61. Waldo SW, Li Y, Buono C, Zhao B, Billings EM, Chang J, Kruth HS: Heterogeneity of human macrophages in culture and in atherosclerotic plaques. Am J Pathol 2008, 172:1112-1126.

62. Bresnihan B, Youssef P: Macrophages in rheumatoid arthritis. In The Macrophage.. 2 edition. Edited by: Burke B, Lewis CE. Oxford: Oxford University Press; 2002:231-433.

\section{doi:10.1186/ar3796}

Cite this article as: Ambarus et al:: Intimal lining layer macrophages but not synovial sublining macrophages display an IL-10 polarized-like phenotype in chronic synovitis. Arthritis Research \& Therapy 2012 14:R74.

\section{Submit your next manuscript to BioMed Central and take full advantage of:}

- Convenient online submission

- Thorough peer review

- No space constraints or color figure charges

- Immediate publication on acceptance

- Inclusion in PubMed, CAS, Scopus and Google Scholar

- Research which is freely available for redistribution

Submit your manuscript at www.biomedcentral.com/submit
Biomed Central 